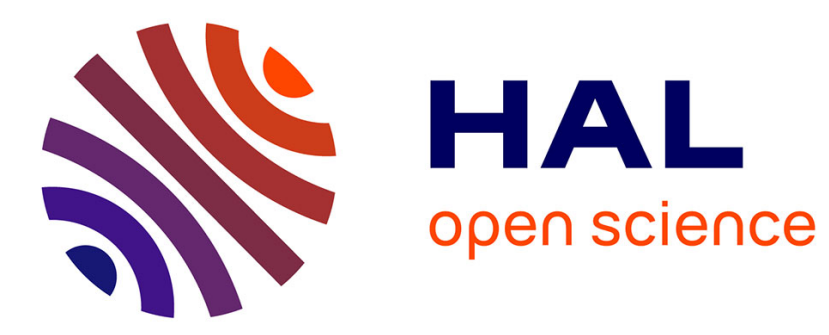

\title{
Ionization of short weak polyelectrolytes: when size matters
}

Caterina Dolce, Guillaume Mériguet

\section{To cite this version:}

Caterina Dolce, Guillaume Mériguet. Ionization of short weak polyelectrolytes: when size matters. Colloid and Polymer Science, 2016, 10.1007/s00396-016-4000-x . hal-01423298

\section{HAL Id: hal-01423298 \\ https://hal.sorbonne-universite.fr/hal-01423298}

Submitted on 5 Jan 2017

HAL is a multi-disciplinary open access archive for the deposit and dissemination of scientific research documents, whether they are published or not. The documents may come from teaching and research institutions in France or abroad, or from public or private research centers.
L'archive ouverte pluridisciplinaire HAL, est destinée au dépôt et à la diffusion de documents scientifiques de niveau recherche, publiés ou non, émanant des établissements d'enseignement et de recherche français ou étrangers, des laboratoires publics ou privés. 


\title{
Ionization of short weak polyelectrolytes: when size matters
}

\author{
Caterina Dolce · Guillaume Mériguet
}

\begin{abstract}
The ionization of short weak polyelectrolytes in dilute solutions is investigated by ${ }^{1} \mathrm{H}$ Nuclear Magnetic Resonance (NMR). The increase of the $\mathrm{pH}$ of the medium causes both the ionization of the polyacids and, due to the intramolecular repulsions, the swelling of the chains. As a result, a noticeable effect of the $\mathrm{pH}$ change on the NMR chemical shift $\delta$, and on the self-diffusion coefficient $D$ is observed. The ionization of the polyelectrolyte occurs at higher $\mathrm{pH}$ as the length of the chain increases. The variation of the selfdiffusion coefficient with $\mathrm{pH}$ exhibits the opposite dependence on the length of the chain. However, no detectable effect of the length of the polyelectrolyte chain on the evolution of the chemical shift with $\mathrm{pH}$ is observed. These apparent contradictions are examined to clarify the impact of the chain length on the polyelectrolyte properties, and the counterion role in the ionization process.
\end{abstract}

\section{Introduction}

According to the nature of their ionic group and their behavior with $\mathrm{pH}$, polyelectrolytes fall into two distinct categories: strong and weak polyelectrolytes. For strong polyelectrolytes, the distribution of charge is not sensitive to $\mathrm{pH}$, whereas for weak polyelectrolytes the amount of charged sites varies as a function of $\mathrm{pH}$. For weak polyelectrolytes, the charging process and the associated structural and dynamics outcomes have to be known and controlled in order to take advantage of the polyelectrolyte in its potential applications. For example, the modification of the state of charge of a polyelectrolyte makes it possible to tune its hydrophobicity, which is useful for the decolorization of dye

Sorbonne Universités, UPMC Univ Paris 06, CNRS

Laboratoire PHENIX

case 51, 4 place Jussieu, F-75005 Paris, France

E-mail: guillaume.meriguet@upmc.fr solutions [1]. Another example is the power conversion efficiency in polymer solar cells, which is governed by the protonated state of the conjugated polyelectrolytes [2].

Among weak polyelectrolytes, polyacrylic acid (PAA) has a specific interest since it is widely used in household and industry products as a scale inhibitor or thickening agent $[3,4]$. In addition, PAA can be seen as a model for natural organic polyacids which are at play in various environmental processes, such as the facilitated transport of heavy metals or radionuclide ions [5]. Furthermore, though a noticeable number of studies have been devoted to polyelectrolytes, especially PAA, the vast majority have so far focused on long chain polyelectrolytes since they are compatible with scaling approaches or infinitely long chain descriptions [6, 7]. However, some applications use short chain polyelectrolytes $[8,9]$, for which the validity of the theoretical developments and scaling laws needs to be examined, especially for systems where the length of the chain is in the order of few persistence lengths.

The present work focuses on the ionization process of the sodium polyacrylate (PAANa) of different molecular weights. Beyond the evaluation of the ionization ratio $\alpha$, the present work relies on two NMR observables to assess the consequences of the ionization and to investigate the infuence of the polyelectrolyte chain length. A recent study [10] claims that the conformational transition with the $\mathrm{pH}$ does not occur for short chain polyacrylate $\left(M_{n}<16.5 \mathrm{kDa}\right)$. The present study aims at shedding some light on this debated transition starting from simple carboxylic acids up to short chain polyelectrolytes $(N \sim 100)$. We therefore intend to assess the influence of the molecular weight on the diffusion and evaluate the consequences of a $\mathrm{pH}$ change on the protonation, the self-diffusion, and the local environment via the NMR chemical shift.

To address these issues, we take advantage of the diffusion NMR technique [11-13]. NMR is a versatile technique to study the conformation and structure of polymer 
chains $[14,15]$. NMR diffusion can quantify the mobility of polyelectrolytes [16] and evaluate the association of ions or molecules [17-19]. On the molecular scale, NMR gives insight to the variation of the spin environment, when the protonation state changes through the chemical shift [20]. On a larger length scale (10-100 $\mu \mathrm{m})$, the self-diffusion of the polyelectrolytes can be investigated using the Pulsed Field Gradient NMR (PFG-NMR) method. In contrast to fluorescence correlation spectroscopy (FCS), that measures the diffusion coefficients thanks to fluorescent moieties in the diffusing species $[6,21]$, NMR does not need the grafting of additional external species that might alter the dynamics [22]. Furthermore, diffusion NMR is not affected by the limitations of the dynamic light scattering (DLS), from which diffusion coefficients can also be determined. DLS measures concentration fluctuations and hence collective (mutual) diffusion coefficients [23]. DLS is not suited for small molecule while diffusion NMR is a method of choice. Therefore, NMR is a powerful tool to determine the absolute value of the diffusion coefficient and to assess the effects of the medium [11, 13].

This paper is organised as follows. First, the samples and the methods used are presented in the experimental section. Secondly, the ionization of the polyectrolytes is determined with acid-base titration and the effect is shortly discussed together with the literature data. Thirdly, the effect of this ionization on the two NMR observables, the chemical shift and the self-diffusion coefficient, are investigated to understand the effects on the polyelectrolyte chain and the influence on the length of the polyelectrolyte.

\section{Experimental section}

\subsection{Materials and methods}

Four PAANa, $\left[-\mathrm{CH}_{2}-\mathrm{CH}(\mathrm{COONa})-\right]_{n}$, of different molecular weights $(M=2.1,5.1,8$ and $15 \mathrm{kDa})$ were purchased from Sigma-Aldrich. The water content of the different products was accounted for during the preparation of the studied samples. NMR spectra and conductivity monitoring during dialysis show that the concentration of impurities is less than $2 \%$. Propionic acid (Alfa Aesar, 99\%), glutaric acid (Alfa Aesar, 99\%) and 1,3,5-pentanetricarboxylic acid (TCI, > 98\%) were used for comparison. Unless otherwise stated, all experiments were performed at $298 \mathrm{~K}$. The details of PAANa are reported in the Table $1 . M$ is the approximate weight averaged molecular weight in Dalton given by the provider. $M_{w}$, the weight-average molecular weight, and $M_{n}$, the numberaverage molecular weight, were obtained from size exclusion chromatography (SEC) with an Ultimate 3000 RSLC system in aqueous solution of sodium nitrate $\left(0.1 \mathrm{~mol} \mathrm{~L}^{-1}\right)$ to minimize ionic effects. Shodex $\mathrm{OH}-$ pak $30 \mathrm{~cm}$ columns were used (802.5HQ, 804HQ, 806HQ and 807HQ) in series.

\begin{tabular}{ccccccc}
\hline$M$ & $M_{w}$ & $M_{n}$ & $N_{w}$ & $R_{\mathrm{h}}$ & $\ell_{\max }$ & $c^{\star}$ \\
\hline 2.1 & 2.7 & 1.8 & 22 & 1.2 & 6 & 217 \\
5.1 & 5.8 & 3.5 & 54 & 1.7 & 14 & 147 \\
8 & 8 & 4.5 & 85 & 2.2 & 21 & 87 \\
15 & 13.7 & 7.1 & 160 & 2.6 & 40 & 84 \\
\hline
\end{tabular}

Table 1 Structural features of PAANa with different molecular mass in $\mathrm{kg} \mathrm{mol}^{-1}, M$ (label value from the provider). $M_{w}$ is the weight-average molecular weight, $M_{n}$ is the number-average molecular weight, $N_{w}$ is the weight averaged degree of polymerization, $R_{\mathrm{h}}$ in $\mathrm{nm}$ is the hydrodynamic radius obtained from NMR measurements at $\mathrm{pH} \sim 8, \ell_{\max }$ in $\mathrm{nm}$ is the max end-to-end distance is obtained from monomers' number and length, and $c^{\star}$ in $\mathrm{kg} \mathrm{m}^{-3}$ is the overlap concentration obtained from Equation 1.

Since Multi-Angle Light Scattering (MALS) was coupled with the SEC separation, no calibration standard sample was used. This characterization was performed by the Institute Charles Sadron (Strasbourg - France). $N_{w}$ is the weight averaged degree of polymerization obtained from molecular mass of polymer and of the monomer $\left(M_{m}\right), N_{w}=M_{w} / M_{m}[24$, 25]. $R_{\mathrm{h}}$ is the hydrodynamic radius obtained from NMR measurements at $\mathrm{pH} \sim 8$, using Stokes-Einstein equation $R_{\mathrm{h}}=k_{\mathrm{B}} T /(6 \pi \eta D)$ as also calculated by [26]. Where $k_{\mathrm{B}}$ is the Boltzmann constant, $T$ is the temperature $(T=298 \mathrm{~K})$ and $\eta$ is the viscosity of the solvent at $298 \mathrm{~K}\left(10 \% \mathrm{D}_{2} \mathrm{O}\right.$ and $90 \% \mathrm{H}_{2} \mathrm{O}, 930 \mu \mathrm{Pa} \mathrm{s}$ ) [27]. The maximum end-toend distance $\ell_{\max }$ is calculated from monomers' number $N_{w}$ and length $a, \ell_{\max }=N_{w} \cdot a$. The value of $a$ was obtained from SAXS experiments $(a=0.252 \mathrm{~nm})[24,25] . c^{\star}$ is the value of overlap or crossover concentration, specific of each mass, above which the entanglement occurs. Indeed, polyelectrolyte chains begin to overlap when the distance between them is in the order of their size. The geometrical definition of the overlap concentration depends on the conformation of the chain [28]. The radius of gyration is often used for coiled conformations, whereas the contour length is used for rod-like chains. In the present study, $c^{\star}$, is estimated with the hydrodynamic radius $R_{\mathrm{h}}$, which is an indirect measure of the conformation:

$c^{\star}=\frac{M_{n}}{N_{\mathrm{A}}\left(2 R_{\mathrm{h}}\right)^{3}}$

where $N_{\mathrm{A}}$ is the Avogadro constant.

The PAANa solutions were prepared at weight fraction of $\sim 1 \%$ in MilliQ water. The range of concentrations studied lies below the estimated $c^{\star}$, as confirmed by the linear dependence of the self-diffusion on concentration (Figure S1 - Electronic Supplementary Material). Indeed when $c>c^{\star}$, the expected concentration dependence would be a power law [29]. In this regime, the effect of inter-chain interactions is weak compared to the intra-chain interactions, and thus changes in diffusion can then mainly be ascribed to changes in conformation of the chain. 
The $\mathrm{pH}$ was varied with $\mathrm{NaOH}$ (Chem-Lab) and $\mathrm{HCl}$ (Chem-Lab) solutions at $1.000 \pm 0.002 \mathrm{~mol} \mathrm{~L}^{-1}$. For NMR measurements, $500 \mu \mathrm{L}$ of each solution and $100 \mu \mathrm{L}$ of $\mathrm{D}_{2} \mathrm{O}$ (CEA-ORIS, isotopic content $\geq 99.8 \%$ ) were transferred in a conventional $5 \mathrm{~mm}$ NMR tube.

\subsection{Titration}

Titration were performed with the titrator DT1200 from Dispersion Technology. Measurements were carried out at room temperature with 50 titrant doses, adjusted from 30 to $300 \mu \mathrm{L}$.

Samples were prepared at $\sim 1 \mathrm{wt} \%$ and diluted 10 times using MilliQ water, the final molarity of the polyelectrolyte units was around $0.01 \mathrm{~mol} \mathrm{~L}^{-1}$. The initial $\mathrm{pH}$ of this system is $\sim 9$. The titrant was $\mathrm{HCl}\left(0.1000 \pm 0.0002 \mathrm{~mol} \mathrm{~L}^{-1}\right.$, Carl-Roth). The proportion of ionized sites, or deprotonation degree $\alpha$, of the polyelectrolyte is calculated from the difference of the amounts of protons bound to the polyelectrolyte and those remaining in solution as measured by $\mathrm{pH}$.

\subsection{Nuclear Magnetic Resonance}

NMR measurements were carried out on a Bruker Avance DRX 500 NMR spectrometer operating at $499.76 \mathrm{MHz}$ for ${ }^{1} \mathrm{H}$, with a maximal magnetic gradient field achievable of $57 \times 10^{-2} \mathrm{~T} \mathrm{~m}^{-1}$. Data were recorded in $90 \% \mathrm{H}_{2} \mathrm{O}-10 \%$ $\mathrm{D}_{2} \mathrm{O}$ mixture (residual HOD, peak at $4.7 \mathrm{ppm}$ ) for locking purpose. The sample temperature was controlled by a Bruker BCU and set to $298.0 \mathrm{~K} .{ }^{13} \mathrm{C}$ experiments were also performed using the broadband channel of the $\mathrm{BBO}$ probe.

In an aqueous solution, the strong water signal would cover the polyelectrolyte signal and create a strong baseline distortion in the NMR spectra [30]. To avoid this effect which limits the capacity to measure the diffusion coefficient in aqueous solutions, a low power presaturation pulse of water signal was used during the recycle delay. To obtain the diffusion coefficient, the pulsed field gradient (PFG) stimulated echo sequence BPP-LED (ledbpgppr2s Bruker sequence) with a water presaturation was used [31, 32].

The pulse gradient were sine-shaped and their duration $\delta$ was $5 \mathrm{~ms}$. The diffusion delay $\Delta$ was $0.200 \mathrm{~s}$ and the field gradient amplitude $g$ was varied with 16 increments, from $2 \%$ to $80 \%$ of the maximum field gradient amplitude. To obtain each spectrum, sixteen measurements were averaged and for each sample four spectra were acquired.

The resultant signal intensity $I(b)$, depends on the diffusion sensitivity factor $b$ and on the diffusion coefficient $D$. The diffusion sensitivity factor is equal to $b=\gamma^{2} g^{2} \delta^{2}(\Delta-$ $\delta / 3-\tau / 2)$, where $\gamma$ is the gyromagnetic ratio of the nucleus and $\tau(400 \mu \mathrm{s})$ is a delay for the gradient recovery. The value of the gradient was calibrated with the value of the self-diffusion coefficient of $\mathrm{HOD}$ in $\mathrm{D}_{2} \mathrm{O}[33,34]$.
Furthermore, when using NMR experiments on polymer solutions, particular expedients have to be considered to analyze the signal. Polymer systems are generally characterized by a range of molecular weights [35] that give rise to a distribution of molecular sizes and then a distribution of selfdiffusion coefficients. Therefore, due to the diffusion coefficient dispersity, at high $b$ values the signal deviates from a simple single exponential and a mono-exponential fit leads to a significant underestimation of the average diffusion coefficient $\langle D\rangle$. To fit the data satisfactorily, it is then necessary to take into account this departure [16, 19, 36-39], using for example the following second order expansion:

$$
\begin{aligned}
\frac{I(b)}{I(b=0)} & =\int_{0}^{\infty} P(D) \exp (-b D) \mathrm{d} D \\
& \simeq \exp \left(-b\langle D\rangle+\frac{1}{2} b^{2}\left(\left\langle D^{2}\right\rangle-\langle D\rangle^{2}\right)\right)+\cdots
\end{aligned}
$$

where the first cumulant $\langle D\rangle$ is the average diffusion coefficient, and the second $\left\langle D^{2}\right\rangle-\langle D\rangle^{2}$, gives access to the width of the distribution. Besides, the observed diffusion coefficient distribution might differ from the real diffusion coefficient distribution because of the relaxation effects during the application of the pulse sequence. A detailed analysis of this effect on the average diffusion coefficient would lie out of the scope for this paper, but this effect was quantified and was found to be of the order of the experimental uncertainty. The analysis of the decay was then fitted by equation 3 with the first and second cumulants as free parameters, but only the average diffusion coefficient $\langle D\rangle$ will be discussed further in the present work. The diffusion coefficients reported in the following, are an average of the diffusion coefficients of the $\mathrm{CH}$ and $\mathrm{CH}_{2}$ peaks. A repeatability error of the $2 \%$ is associated to the diffusion coefficient.

\section{Results and Discussion}

\subsection{Titration}

The protonation of polyelectrolytes has been widely studied [40] and will not be described in detail here. Only the main features of interest will be discussed as a reference for comparison with the properties measured by NMR. To assess the charge properties of the polyelectrolyte with $\mathrm{pH}$, acid-base titrations of PAANa were carried out. In Figure 1, four PAANa with different lengths are shown together with the three carboxylic acids. All curves show a sigmoidal increase of the fraction of deprotonated sites $\alpha$, with $\mathrm{pH}$, in agreement with literature data $[6,41]$.

For a simple carboxylic acid $(N=1)$, the degree of ionization $\alpha$ can be described by the Henderson-Hasselbalch equation $[42,43]$ :

$\mathrm{pH}=\mathrm{p} K+\log \frac{\alpha}{1-\alpha}$ 


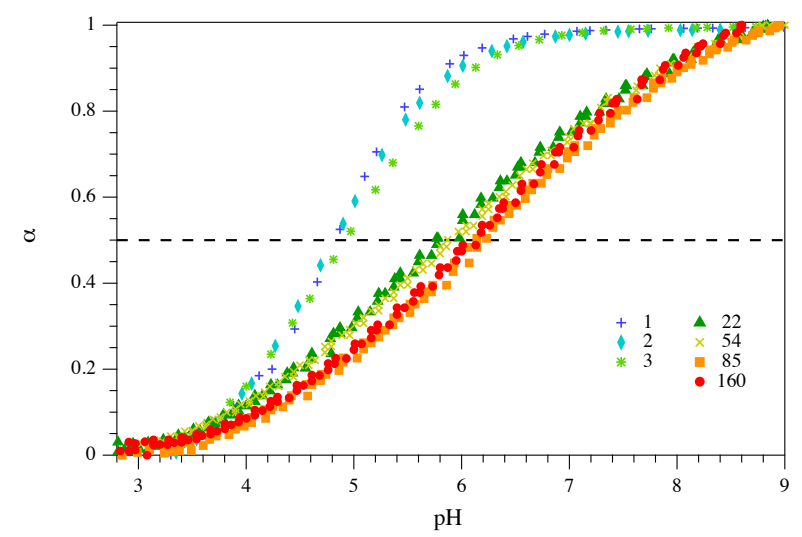

Fig. 1 Fraction of deprotonated sites $\alpha$ as a function of $\mathrm{pH}$. Titration for different molecules: propionic acid $(N=1,+)$, glutaric acid $(N=$ $2, \downarrow), 1,3,5$-pentanetricarboxylic acid $(N=3, *), 2.1 \mathrm{kDa}(N=22, \boldsymbol{\Delta})$, $5.1 \mathrm{kDa}(N=54, \times), 8 \mathrm{kDa}(N=85, \boldsymbol{\square}), 15 \mathrm{kDa}(N=160, \bullet)$. The dashed line marks $\alpha=0.5$.

For polycarboxylic acids $(N>1)$, the slope of $\alpha \mathrm{vs} \mathrm{pH}$ decreases. For polyelectrolytes, the protonation is strongly influenced by the state of charge of nearby sites. As a result, even if a sigmoidal shape of the titration curve is obtained, the slope deviates from the Henderson-Hasselbalch behavior (equation 4). Several models can be used to describe this deviation: a smeared out charge model [40], a Poisson-Boltzmann description [41], a "neighbour effect" model [44], or Monte-Carlo simulations either with implicit or explicit counterions [45-47]. One even simpler approach is to consider the $\mathrm{pH}$ value for which half of the sites are ionized ( $\alpha=0.5$, horizontal line in Figure 1), the midpoint of the ionization process, as an estimate of an effective $\mathrm{p} K$, noted $p_{\alpha}$ hereafter. The effect of the chain length is clearly noticeable in Figure 1 . The observed $p_{\alpha}$ increases with the length of the polyelectrolyte. This effect could be related to the difficulty to ionize high molecular weight polyelectrolytes, because of the increase of the electrostatic potential with $M_{w}[6,45]$. These values are slightly lower than values of $p_{\alpha}$ found by Laguecir et al.[6], certainly due to the difference in concentration and salinity between the samples. Ullner et al. [46, 47] have studied the phenomenon using Monte-Carlo simulations and a scaling approach, they have suggested the following law for the deviation from the noncharged $\mathrm{p} K$ :

$p_{\alpha}-\mathrm{p} K_{\mathrm{a}} \sim \alpha^{\frac{1}{3}}(\ln N)^{\frac{2}{3}}$

The deviations of $p_{\alpha}$ values from the $\mathrm{p} K_{\mathrm{a}}$ of the propionic acid $(N=1)$, and equation 5 are reported in Figure S2 (Electronic Supplementary Material). A rather fair agreement between the data and Ullner relation is observed.

\subsection{Nuclear Magnetic Resonance}

In this section, ${ }^{1} \mathrm{H}$ NMR $(500 \mathrm{MHz})$ was used to access information on the local environment via the chemical shift $\delta$ and on the self-diffusion via the measurement of the diffusion coefficient $D$.

\subsubsection{Analysis of ${ }^{1} \mathrm{H}$ spectra}

The ${ }^{1} \mathrm{H}$ NMR spectrum of PAANa $15 \mathrm{kDa}$ is shown in Figure 2. Two families of peaks, corresponding to the two different types of hydrogens in the PAANa chain, has been identified. This assignment was confirmed by DEPT-135 and ${ }^{13} \mathrm{C}-{ }^{1} \mathrm{H}$ HSQC experiments where the number of hydrogen atoms attached to each carbon is determined unambiguously (data not shown). In Figure 2, the peak centered around $2.02 \mathrm{ppm}$ at $\mathrm{pH}=8.8$ is associated to methine groups $(\mathrm{CH})$ and the peak centered at $1.42 \mathrm{ppm}$ is associated to methylene groups $\left(\mathrm{CH}_{2}\right)$. The splitting observed is due to the various configurations of the carboxylate groups with respect to the chain, i.e. the tacticity.

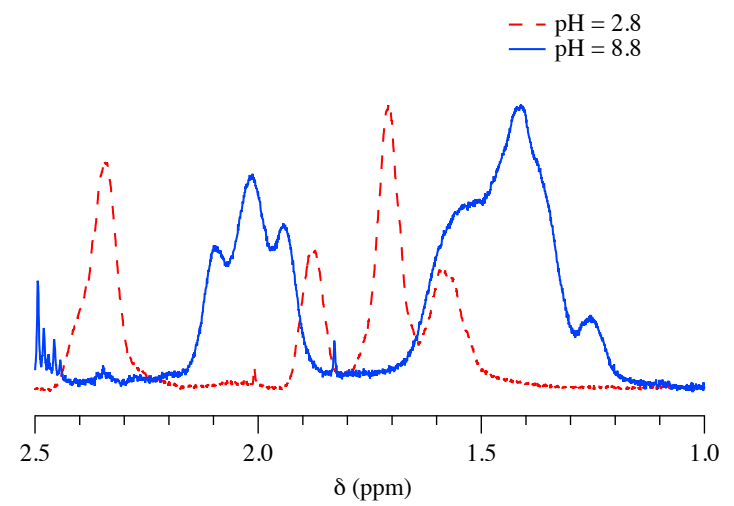

Fig. $2{ }^{1} \mathrm{H}$ NMR (500 MHz) spectra of PAANa $15 \mathrm{kDa}$ at $\mathrm{pH}=8.8$ (solid line) and $\mathrm{pH}=2.8$ (dashed line).

The effects of $\mathrm{pH}$ on the ${ }^{1} \mathrm{H}$ NMR spectrum are reported in Figure 2. As seen in Figure 2, the chemical shift changes with the $\mathrm{pH}$ : $\delta$ decreases when the $\mathrm{pH}$ increases, because of the dependence on the protonation state of adjacent acidic or basic sites [40].

In basic medium, the shielding of the magnetic field is higher because the protons are richer in electrons and a lower $\delta$ value is observed. This behavior has already been identified for protons located in the $\alpha$ position of small carboxylic acids [48]. The opposite trend is observed for ${ }^{13} \mathrm{C}$, for which the chemical shift is seen to increase with the $\mathrm{pH}$ (Figure $\mathrm{S} 3$ - Electronic Supplementary Material), with a largest variation for the carboxyl carbon. This is in agreement with the previous results for small carboxylic acids [49] or longer 
PAA chains [50]. The polarization of the $\mathrm{C}-\mathrm{H}$ bond could be the cause of the two opposite evolutions of the chemical shifts of ${ }^{13} \mathrm{C}$ and ${ }^{1} \mathrm{H}[51,52]$, but an effect of conformational change cannot be disregarded at this stage [53, 54].

To check the effect of the electrostatic interaction, the influence of added salt on the chemical shift has been examined. The moderate addition of salt (up to $1 \mathrm{~mol} \mathrm{~L}^{-1}$ ) has no noticeable effect on the chemical shift of the polyacrylate (Figure S4 left - Electronic Supplementary Material). However, up to $0.1 \mathrm{~mol} \mathrm{~L}^{-1}$ of added salt, a noticeable effect on the conformation is observed with a change of the diffusion coefficient (Figure S4 right - Electronic Supplementary Material). The effect of conformation on the chemical shift in the present case can then be considered as weak compared to the effect of bond polarization.

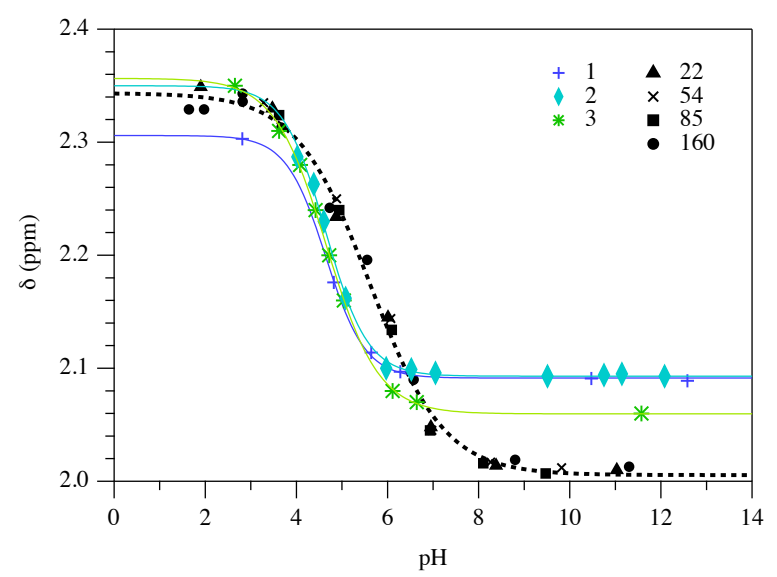

Fig. 3 Chemical shift $\delta$ (ppm) versus $\mathrm{pH}$ value for $\alpha$-protons: propionic acid $(N=1,+)$, glutaric acid $(N=2, \diamond), 1,3,5$ pentanetricarboxylic acid $(N=3, *), 2.1 \mathrm{kDa}(N=22, \mathbf{\Delta}), 5.1 \mathrm{kDa}$ $(N=54, \times), 8 \mathrm{kDa}(N=85, \mathbf{\square}), 15 \mathrm{kDa}(N=160, \bullet)$.

To study the influence of the chain length, the spectra of polyelectrolytes of different molecular mass were acquired (2.1, 5.1, 8 and $15 \mathrm{kDa})$ together with the small carboxylic acids. For all molecules, the chemical shift decreases with increasing $\mathrm{pH}$. In Figure 3, the chemical shifts $\delta$ of the protons in $\alpha$ position with respects to the carboxylate group (CH in PAA chain) as a function of $\mathrm{pH}$ are reported. Surprisingly, while small differences can be seen for the small carboxylic acids, the global variation of $\delta$ appears to be independent from the molecular mass for the PAA chains. All the data are well fitted with a unique sigmoidal curve (dotted curve in the Figure 3):

$\delta(\mathrm{pH})=\delta_{\text {acid }}+\frac{\delta_{\text {basic }}-\delta_{\text {acid }}}{1+\exp \left(\frac{p_{\delta}-\mathrm{pH}}{k}\right)}$

with a resulting midpoint $p_{\delta}=5.6 \pm 0.1$ and $k=0.81 \pm 0.05$. The decrease of this curve is slower than for the small carboxylic acids which follow closely the Henderson-Hasselbalch equation $(k=1 / \ln 10=0.44)$. This departure from the Henderson-Hasselbalch equation suggests the existence of a charge regulation process during the deprotonation, as observed for the degree of ionization $\alpha$.

If the chemical shift $\delta$ and the ionization degree $\alpha$ both exhibit a sigmoidal variation with $\mathrm{pH}, \alpha$ shows a molecular mass dependence, not seen for $\delta$. To explain this difference, we have to consider the physical origin of $\alpha$ and $\delta$. The titration measures the macroscopic amount of protons exchanged in the solution, this number is directly related to the chain length and does not measure the counterion condensation. The NMR chemical shift $\delta$, is a microscopic measure of how the magnetic field is shielded for the nucleus. As discussed before, it is correlated to the $\mathrm{C}-\mathrm{H}$ bond polarization due to the local electric field. It depends indirectly on the number of sites deprotonated and on the amount of sodium ions condensed. As shown before, a significant fraction of the deprotonated sites is compensated by the sodium counterions.

To assess the extent of this phenomenon, the Manning parameter $\xi$ can be computed. The distance between neighbouring monomers is $a=0.252 \mathrm{~nm}[24,25]$, . The Bjerrum length, $\ell_{\mathrm{B}}=e^{2} / 4 \pi \varepsilon_{0} \varepsilon_{\mathrm{r}} k_{\mathrm{B}} T=0.71 \mathrm{~nm}$ at $298 \mathrm{~K}$, is the distance at which the electrostatic interaction between two elementary charges is equal to the thermal energy $k_{\mathrm{B}} T$. The Manning parameter $\xi$, that compares the two lengths [55], is defined as $\xi=\ell_{\mathrm{B}} / a=2.84$. Since $\xi>1$, Coulomb interaction dominates over the thermal energy and the condensation of counterions occurs. The value of $\xi \simeq 3$ shows that the length of three repeating units is close to the Bjerrum length, and suggests then that $2 / 3$ of the sites are compensated by the condensation of sodium counterions when the chain is completely deprotonated. This estimation is consistent with previous conductivity measurements [5] and ${ }^{23} \mathrm{Na}$ diffusion NMR experiments (Fig. S5 - Electronic Supplementary Material).

The counterion condensation decreases the electrostatic field and consequently the value of the transition midpoint observed for the chemical shift $\delta$ is lower than that for $\alpha$, where the sodium condensation is not taken into account. Moreover, the length of the polyelectrolyte does not cause any noticeable changes, since the chemical shift is sensitive only to the local environment. The values of midpoints for $\delta\left(p_{\delta}\right)$ and $\alpha\left(p_{\alpha}\right)$ are closer for the shortest chain or even equal for the small carboxylic acid within the experimental uncertainty for which no significant condensation occurs. Conversely, the longer the chain, the higher is the deviation between the two midpoint values. The NMR chemical shifts should then be used with caution to determine the degree of deprotonation and the $\mathrm{p} K_{\mathrm{a}}$ for large molecules where ion condensation occurs. 


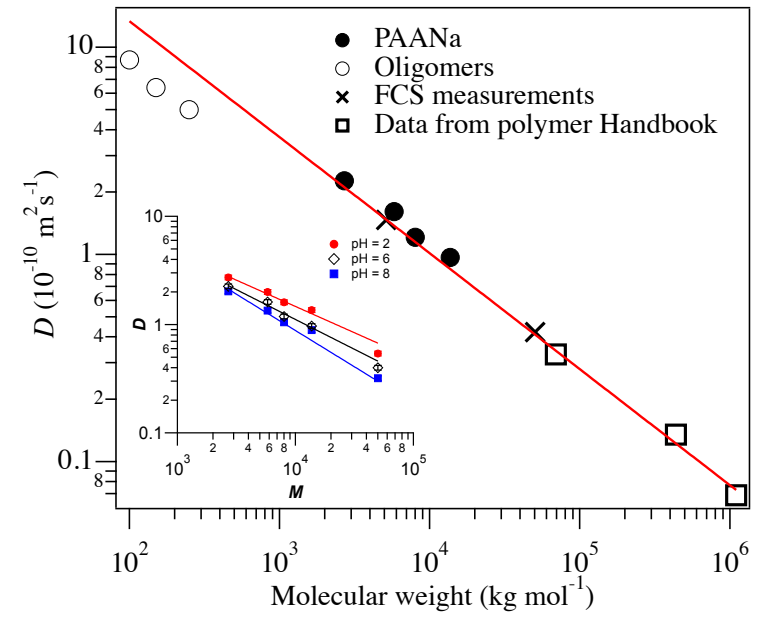

Fig. 4 Diffusion coefficient of PAANa $(\bullet)$ and small carboxylic acids (o) at $\mathrm{pH}=6$ as a function of molecular weight obtained by diffusion NMR. Data obtained by fluorescence correlation spectroscopy $(\times,[6])$ and from the Polymer Handbook ( $\square$, [3]) for a concentration of added salt of $10 \mathrm{mM}$ of $\mathrm{NaCl}$. Inset: effect of $\mathrm{pH}$ on the evolution of the diffusion coefficient with molecular weight.

\subsubsection{Diffusion}

So far, NMR has given information on the local environment, but NMR is also a powerful technique to study the diffusion of the polyelectrolytes on larger scale. To understand the variation of the self-diffusion with the molecular mass, the diffusion coefficients of PAANa as a function of the molecular weight at $\mathrm{pH}=6$, are reported in Figure 4 together with the values for the small carboxylic acids. The values for longer chains from the literature are also reported for comparison [3,6] with a concentration of added salt of $10 \mathrm{mM}$ of $\mathrm{NaCl}$. All the data for the polymeric chains are well fitted with the expression $D(M) \propto M^{-v}$ with $v=0.56$, except the points corresponding to the small carboxylic acids that depart from this law certainly due to their too small size. The value of $v$ found is in agreement with the literature values determined by light scattering in a good solvent $[7,56]$. To understand the physical meaning of the value of $v$ found, it is compared with theoretical values for different conformations:

-0.3 is the $v$ value for a hard ellipsoid [57],

- 0.6 is the value for a random coil chain,

- 1.0 is the value for a rod-like particle [38].

The same analysis was carried out at $\mathrm{pH}=2$ and $\mathrm{pH}=8$ (see figure 4 - inset). At $\mathrm{pH}=2$, the exponent $v$ is equal to $0.49 \pm 0.05$ showing that the conformation is more compact at low $\mathrm{pH}$. At $\mathrm{pH}=8$, the value of $v=0.67 \pm 0.05$ found shows that the chain cannot be seen as a rigid rod and adopts a more flexible conformation. This last result is consistent with viscosimetric determination at low salt concentration [58].
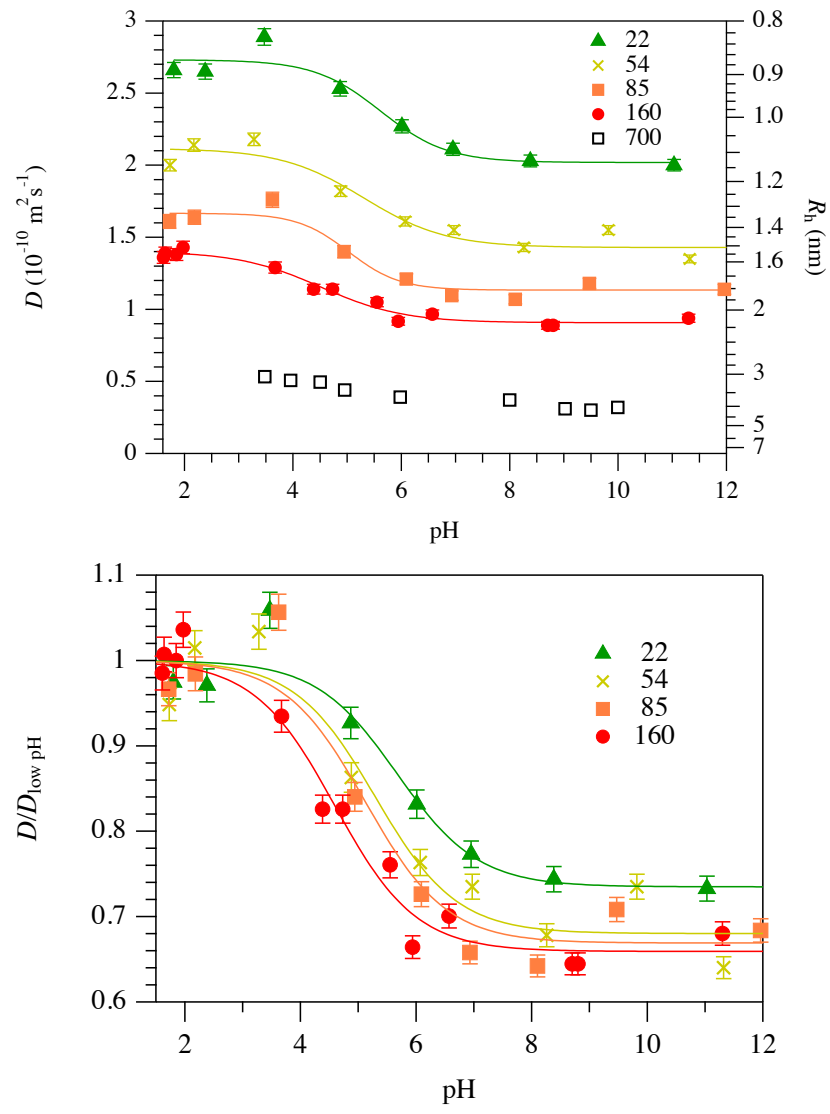

Fig. 5 Top: Diffusion coefficient and hydrodynamic radius versus $\mathrm{pH}$ for different molecular mass of PAANa: $2.1 \mathrm{kDa}(N=22, \boldsymbol{\Lambda}), 5.1 \mathrm{kDa}$ $(N=54, \times), 8 \mathrm{kDa}(N=85, \boldsymbol{\square})$ and $15 \mathrm{kDa}(N=160, \bullet)$. The data of the PAANa $50 \mathrm{kDa}$ (obtained by FCS) come from the literature [6] $(N=700, \square)$. Bottom: same data normalized by the diffusion coefficient at $\mathrm{pH} \sim 2$.

The evolution of the diffusion coefficients of PAANa $2.1,5.1,8$ and $15 \mathrm{kDa}$ as a function of $\mathrm{pH}$ are reported in Figure 5 together with data of PAANa $50 \mathrm{kDa}$ (obtained by FCS) from the literature [6]. The diffusion coefficients decrease with a sigmoidal behavior since at high $\mathrm{pH}$, the PAANa is fully charged and the electrostatic interaction is strong enough to stretch the polyelectrolyte chain. The observed increase of the hydrodynamic radius is also consistent with the evolution of the radius of gyration with the increase of the ionization degree $\alpha$ observed by Monte Carlo simulations [6, 45]. Carnal et al. [45] have simulated using the Monte-Carlo simulation an isolated weak polyelectrolyte of 100 monomers at several $\mathrm{pH}$ values. At a high $\mathrm{pH}$, they found that an extended structure is achieved to minimize the long-range electrostatic energy.

Moreover, as seen in Figure 5 (bottom), the relative variation of the diffusion coefficient with the $\mathrm{pH}$ is size-dependent. This variation increases with the molecular weight, from $26 \%$ for the $2.1 \mathrm{kDa}$ to $34 \%$ for $15 \mathrm{kDa}$ PAANa. This trend is also observed in the data of Swift et al. [10] where the decrease of $D$, between acidic and basic conditions, varies 


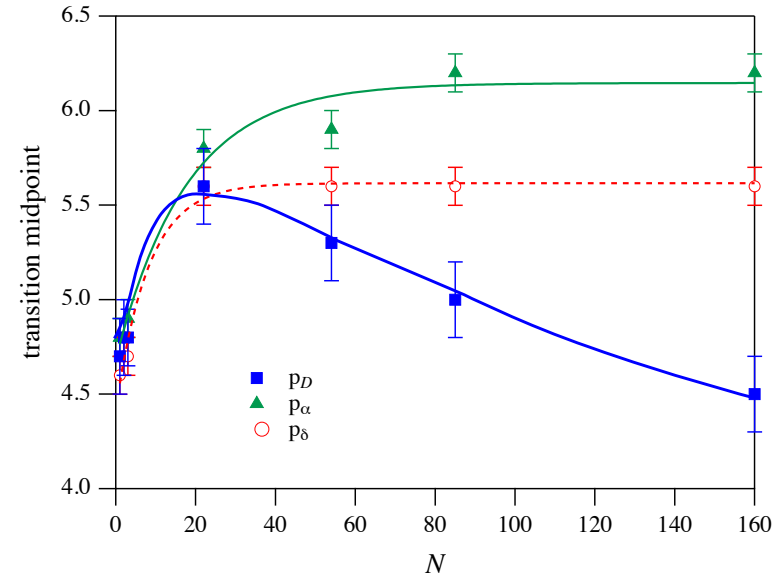

Fig. 6 Inflection points of the previous measurements as a function of $\mathrm{pH}$, versus the degree of polymerization. $p_{D}$ is related to the diffusion coefficient in Figure $5(\boldsymbol{\square}) ; p_{\alpha}$ to $\alpha$ in Figure $1(\circ) ; p_{\delta}$ is the midpoint for the chemical shift in Figure $3(\boldsymbol{\Delta})$.

from 50 to $75 \%$ while the mass varies from $17 \mathrm{kDa}$ to $55 \mathrm{kDa}$. However, contrary to the results of Swift et al. [10], the change of diffusion coefficient is even observed for low molecular weight PAANa (down to $M_{w}=2.1 \mathrm{kDa}$ ). Actually, the small carboxylic acids also display a transition between acid and basic forms (Figure S6 - Electronic Supplementary Material) consistently with the results of Dunn et al. [59]. For low molecular weight species, this change of diffusion could be ascribed to a change of solvation between the neutral and the charged species as suggested by Dunn et al. [59]. For longer chains, this solvation phenomenon also occurs, but the main origin of the swelling is the electrostatic interactions as discussed before. The mass dependence of this swelling is consistent with the increase of the electrostatic potential with $M_{w}$ already discussed for the ionization of the chain (\$3.1). The size threshold $(M n<16.5 \mathrm{kDa})$ suggested by Swift et al. [10] does not seem justified since the conformational transition is seen whatever the size of the polyacrylate. However, the present study indeed proves that the extent of the transition in terms of expansion of the hydrodynamic radius is larger for longer chains.

To have a comprehensive view of the the ionization process for the different molecular weight, the data in Figure 5 are fitted with a sigmoidal curve and the midpoints obtained, $p_{D}$, are compared with the previous midpoints versus the molecular weight (Figure 6). The comparison of the different midpoints $\left(p_{D}, p_{\alpha}\right.$ and $\left.p_{\delta}\right)$ points out the complex interplay between the different parameters under study. The constant value of the $p_{\delta}$ proves the local character of $\delta$, that is independent to the molecular weight. For small carboxylic acids, the same value of midpoints $p$ is observed whatever the method. For longer chain polyelectrolytes, a departure is expected. The difference between $p_{\alpha}$ and $p_{\delta}$ was already discussed in \$3.2.1. $p_{D}$ is found to be lower than the other two midpoints as it was already observed in the work of Pristinski et al. [21], for a $72 \mathrm{kDa}$ poly(methacrylic acid) PMAA. In the present case, this departure is found to increase with the molecular weight of the chain. The conformational change with the $\mathrm{pH}$ can be discussed in the light of the persistence length, which measure of how far a polymer chain persists in a given direction. In the case of polyelectrolytes, the persistence length $P$ can be divided into a sum of two contributions: an intrinsic persistence length, due to the rigidity of the chain backbone and an electrostatic persistence length arising from the repulsion between neighbouring ionic sites [60]. The persistence length of long chain PAANa $\left(M_{w}>15 \mathrm{kDa}\right)$ was determined by X-ray scattering measurements by Muroga et al. [25]. $P$ values ranging from 0.8 to $1.5 \mathrm{~nm}$ were found for $\alpha$ varying from 0.1 to 0.85 , and for salinity up to $0.1 \mathrm{~mol} \mathrm{~L}^{-1}$. Molecular dynamics simulations [60] of a single and isolated PAA chain of 50 monomers gave values of $P$ from $0.4 \mathrm{~nm}(\alpha=0)$ to $1.3 \mathrm{~nm}$ $(\alpha=1)$ [60]. For the studied polymeric chains, both the hydrodynamic radii $R_{\mathrm{h}}$ and the max end-to-end distances $\ell_{\max }$ are of the order of few persistence lengths. As a result, they tend to behave as long chain polyelectrolytes but still exhibit slight deviations from this behaviour as the evolutions of the transition midpoints with the length show. The small carboxylic acids are significantly below the persistence length and does not follow the same scaling laws (Figure 4 for example).

\section{Conclusions}

The conformation and the self-diffusion of low molecular mass polyelectrolytes in a dilute regime at different $\mathrm{pH}$, concentrations, and salt concentrations have been investigated using NMR. The small chains investigated in the present study appear to follow the same scaling law for the diffusion coefficient as longer chains studied in the literature and differ from simple carboxylic acids. The diffusion coefficient decreases with the molecular weight with a powerlaw dependence $D(M) \propto M^{-v}$. The data compare well with the literature values at $\mathrm{pH} \simeq 6$. At higher $\mathrm{pH}$, the higher slope indicates that the conformation adopted tends towards a flexible rod when the polyelectrolyte is fully charged. Conversely, the chain is more compact at low $\mathrm{pH}$ values.

The charging process of the chain, governed by $\mathrm{pH}$ of the solution, has a noticeable effect on the chemical shift $\delta$ and the diffusion coefficient $D$. While simple carboxylic acids are well described by the Henderson-Hasselbalch equation, the latter equation fails unambiguously for the evolution of the same quantities measured for the polyelectrolytes. Furthermore, as the length of the chain increases, the deprotonation degree $\alpha$, the chemical shift $\delta$ and the diffusion coefficient $D$ give rise to significant differences not observed for the simple carboxylic acids. Whereas the chemical shift 
$\delta$ has a variation with $\mathrm{pH}$ independent of the chain length, $\alpha$ and $D$ display opposite molecular weight dependences. The different molecular weight dependence between $\delta$ and $\alpha$, is related to the different role of the condensation of counterions for the two quantities. The diffusion coefficient shows the swelling of the chain with the ionization. Furthermore, the change of diffusion with the ionization is found to be dependent on the length of the chain. For longer chains, the onset of the diffusion coefficient modification appears at lower $\mathrm{pH}$ and the relative decrease of the diffusion coefficient is larger. The present study shows that even short polyelectrolytes singularly differ from simple carboxylic acids and tend to behave like long chain polyelectrolytes. Finally, their ionization process and its effect on diffusion cannot be easily derived by a single parameter study, since several phenomena are at play.

Acknowledgements The authors thank Dr. Isabelle Correia (UPMC Sorbonne Universités) for the NMR facilities and technical assistance and B. Ancian for fruitful discussions and UPMC for funding.

\section{Funding}

This study was funded by UPMC.

\section{Conflict of interest}

The authors declare no conflict of interest.

\section{References}

1. Jiang, X., Yin, Y., Wang, C., Tian, X.: Decolorization of anionic dye solutions using the hydrophobically modified polyelectrolytes containing beta-cyclodextrin moieties. Chem. Eng. J. 253, 183189 (2014)

2. Yi, C., Hu, R., Ren, H., Hu, X., Wang, S., Gong, X., Cao, Y.: Protonation process of conjugated polyelectrolytes on enhanced power conversion efficiency in the inverted polymer solar cells. J. Photonics Energy 4, 043,099-043,108 (2014)

3. Brandrup, J., Immergut, E.H., Grulke, E.A.: Polymer Handbook, vol. 2, 4 edn. Wiley Interscience, New York (1999)

4. Knappe, P., Bienert, R., Weidner, S., Thuenemann, A.F.: Poly(acrylic acid): A combined analysis with field-flow fractionation and SAXS. Macromol. Chem. Phys. 211(19), 2148-2153 (2010)

5. Roger, G.M., Durand-Vidal, S., Bernard, O., Mériguet, G., Altmann, S., Turq, P.: Characterization of humic substances and polyacrylic acid: A high precision conductimetry study. Colloids Surf., A 356(1-3), 51-57 (2010)

6. Laguecir, A., Ulrich, S., Labille, J., Fatin-Rouge, N., Stoll, S., Buffle, J.: Size and pH effect on electrical and conformational behavior of poly(acrylic acid): Simulation and experiment. Eur. Polym. J. 42(5), 1135-1144 (2006)

7. Schweins, R., Hollmann, J., Huber, K.: Dilute solution behaviour of sodium polyacrylate chains in aqueous $\mathrm{NaCl}$ solutions. Polymer 44(23), 7131-7141 (2003)

8. Gonzalez, G., de la Cal, J.C., Asua, J.M.: Flocculation efficiency of blends of short and long chain polyelectrolytes. Colloids Surf., A 385(1-3), 166-170 (2011)
9. Yu, S., Xu, X., Yigit, C., van der Giet, M., Zidek, W., Jankowski, J., Dzubiella, J., Ballauff, M.: Interaction of human serum albumin with short polyelectrolytes: a study by calorimetry and computer simulations. Soft Matter 11(23), 4630-4639 (2015)

10. Swift, T., Swanson, L., Geoghegan, M., Rimmer, S.: The pHresponsive behaviour of poly(acrylic acid) in aqueous solution is dependent on molar mass. Soft Matter 12(9), 2542-2549 (2016)

11. Price, W.: NMR Studies of Translational Motion: Principles and Applications. Cambridge Molecular Science. Cambridge University Press (2009)

12. Scheler, U.: NMR on polyelectrolytes. Current Opinion in Colloid \& Interface Science 14(3), 212 - 215 (2009)

13. Callaghan, P.: Translational Dynamics and Magnetic Resonance: Principles of Pulsed Gradient Spin Echo NMR. OUP Oxford (2011)

14. Hatada, K., Kitayama, T.: NMR Spectroscopy of Polymers. Springer Berlin Heidelberg, Berlin, Heidelberg (2004)

15. Saalwächter, K., Reichert, D.: Polymer Applications of NMR. In: Encycl. Spectrosc. Spectrom., pp. 2221-2236. Elsevier (2010)

16. Walderhaug, H., Söderman, O., Topgaard, D.: Self-diffusion in polymer systems studied by magnetic field-gradient spin-echo NMR methods. Prog. Nucl. Magn. Reson. Spectrosc. 56(4), 406425 (2010)

17. Šarac, B., Mériguet, G., Ancian, B., Bešter-Rogač, M.: Salicylate isomer-specific effect on the micellization of dodecyltrimethylammonium chloride: large effects from small changes. Langmuir 29(14), 4460-4469 (2013)

18. Giesecke, M., Mériguet, G., Hallberg, F., Fang, Y., Stilbs, P., Furó, I.: Ion association in aqueous and non-aqueous solutions probed by diffusion and electrophoretic NMR. Phys. Chem. Chem. Phys. 17(5), 3402-3408 (2015)

19. Hostnik, G., Bončina, M., Dolce, C., Mériguet, G., Rollet, A.L., Cerar, J.: Influence of counterions on the conformation of conjugated polyelectrolytes: the case of poly(thiophen-3-ylacetic acid). Phys. Chem. Chem. Phys. 18(36), 25,036-25,047 (2016)

20. Bezencon, J., Wittwer, M.B., Cutting, B., Smiesko, M., Wagner, B., Kansy, M., Ernst, B.: pK(a) determination by H-1 NMR spectroscopy - An old methodology revisited. Journal of Pharmaceutical and Biomedical Analysis 93, 147-155 (2014)

21. Pristinski, D., Kozlovskaya, V., Sukhishvili, S.A.: Fluorescence correlation spectroscopy studies of diffusion of a weak polyelectrolyte in aqueous solutions. J. Chem. Phys. 122(1), 14,907 (2005)

22. McDonough, R., Cueto, R., Phillies, G.D.J., Russo, P.S., Dorman, D., Streletzky, K.A.: Fluorescent Labeling Can Alter Polymer Solution Dynamics. Macromolecules 48(19), 7245-7255 (2015)

23. Sedlák, M.: Structure and dynamics of polyelectrolyte solutions by light scattering. In: T. Radeva (ed.) Physical chemistry of polyelectrolytes, Surfactant Science series, vol. 99, pp. 1-58. Marcel Dekker, Inc, New York (2001)

24. Ise, N., Okubo, T., Yamamoto, K., Kawai, H., Hashimoto, T., Fujimura, M., Hiragi, Y.: Ordered structure in dilute solutions of ionic biopolymers. 2. Small-angle X-ray scattering study of sodium polyacrylate solution. J. Am. Chem. Soc. 102(27), 79017906 (1980)

25. Muroga, Y., Noda, I., Nagasawa, M.: Investigation of local conformations of polyelectrolytes in aqueous solution by small-angle $\mathrm{X}$ ray scattering. 1. Local conformations of poly(sodium acrylates). Macromolecules 18(8), 1576-1579 (1985)

26. Saito, T., Shimada, K., Kinugasa, S.: Determination of the size of a polystyrene nanosphere by the pulsed field gradient nuclear magnetic resonance method. Langmuir 20(11), 4779-4781 (2004)

27. Kestin, J., Khalifa, H., Correia, R.: Tables of the Dynamic and Kinematic Viscosity of Aqueous Nacl Solutions. J. Phys. Chem. Ref. Data 10(1), 71-87 (1981)

28. Teraoka, I.: Polymer Solutions: An Introduction to Physical Properties. John Wiley \& Sons, New York (2002) 
29. Cosgrove, T., Griffiths, P.: The Critical Overlap Concentration Measured by Pulsed-Field Gradient Nuclear-Magnetic-Resonance Techniques. Polymer 35(3), 509-513 (1994)

30. Majer, G., Zick, K.: Accurate and absolute diffusion measurements of Rhodamine 6G in low-concentration aqueous solutions by the PGSE-WATERGATE sequence. J. of Chem. Phys. 142(16), 164,202 (2015)

31. Price, W.S.: Pulsed-field gradient nuclear magnetic resonance as a tool for studying translational diffusion: Part 1. basic theory. Concepts Magn. Reson. 9(5), 299-336 (1997)

32. Wu, D.H., Chen, A.D., Johnson, C.S.: An improved diffusionordered spectroscopy experiment incorporating bipolar-gradient pulses. J. Magn. Reson., Ser. A 115(2), 260-264 (1995)

33. Holz, M., Heil, S.R., Sacco, A.: Temperature-dependent selfdiffusion coefficients of water and six selected molecular liquids for calibration in accurate ${ }^{1} \mathrm{H}$ NMR PFG measurements. Phys. Chem. Chem. Phys. 2(20), 4740-4742 (2000)

34. Holz, M., Weingartner, H.: Calibration in Accurate Spin-Echo Self-Diffusion Measurements Using $\mathrm{H}-1$ and Less-Common Nuclei. Journal of Magnetic Resonance 92(1), 115-125 (1991)

35. Stepto, R.F.T.: Dispersity in polymer science (IUPAC Recommendations 2009). Pure Appl. Chem. 81(2), 351-353 (2009)

36. Callaghan, P.T., Lelievre, J.: The size and shape of amylopectin: A study using pulsed-field gradient nuclear magnetic resonance. Biopolymers 24(3), 441-460 (1985)

37. Håkansson, B., Nydén, M., Söderman, O.: The influence of polymer molecular-weight distributions on pulsed field gradient nuclear magnetic resonance self-diffusion experiments. Colloid Polym. Sci. 278(5), 399-405 (2000)

38. Oostwal, M.G., Blees, M.H., De Bleijser, J., Leyte, J.C.: Chain self-diffusion in aqueous salt-free solutions of sodium poly(styrenesulfonate). Macromolecules 26(26), 7300-7308 (1993)

39. Roding, M., Bernin, D., Jonasson, J., Sarkka, A., Topgaard, D., Rudemo, M., Nyden, M.: The gamma distribution model for pulsed-field gradient NMR studies of molecular-weight distributions of polymers. Journal of Magnetic Resonance 222, 105-111 (2012)

40. Borkovec, M., Jönsson, B., Koper, G.J.M.: Ionization processes and proton binding in polyprotic systems: Small molecules, proteins, interfaces, and polyelectrolytes. In: E. Matijević (ed.) , Surface and Colloid Science, vol. 16, pp. 99-339. Springer US, Boston, MA (2001)

41. Sadeghpour, A., Vaccaro, A., Rentsch, S., Borkovec, M.: Influence of alkali metal counterions on the charging behavior of poly(acrylic acid). Polymer 50(16), 3950-3954 (2009)

42. Henderson, L.J.: Concerning the relationship between the strength of acids and their capacity to preserve neutrality. Am. J. Physiol. 21(2), 173-179 (1908)

43. Hasselbalch, K.A.: Die Berechnung der Wasserstoffzahl des blutes auf der freien und gebundenen Kohlensaure desselben, und die Sauerstoffbindung des Blutes als Funktion des Wasserstoffzahl. Biochem Z. 78, 112-144 (1916)

44. Annenkov, V.V., Kruglova, V.A., Mazyar, N.L.: Analysis of the potentiometric titration curves within the framework of the theory of the "neighbor effect". J. Polym. Sci. Part B Polym. Phys. 36(6), 931-936 (1998)

45. Carnal, F., Ulrich, S., Stoll, S.: Influence of Explicit Ions on Titration Curves and Conformations of Flexible Polyelectrolytes: A Monte Carlo Study. Macromolecules 43(5), 2544-2553 (2010)

46. Ullner, M., Jönsson, B., Söderberg, B., Peterson, C.: A Monte Carlo study of titrating polyelectrolytes. J. Chem. Phys. 104(8), 3048-3057 (1996)

47. Ullner, M., Jönsson, B., Widmark, P.O.: Conformational properties and apparent dissociation constants of titrating polyelectrolytes: Monte Carlo simulation and scaling arguments. J. Chem.
Phys. 100(4), 3365 (1994)

48. Tynkkynen, T., Tiainen, M., Soininen, P., Laatikainen, R.: From proton nuclear magnetic resonance spectra to ph. assessment of ${ }^{1} \mathrm{H}$ NMR pH indicator compound set for deuterium oxide solutions. Anal. Chim. Acta 648(1), 105-12 (2009)

49. Cistola, D.P., Small, D.M., Hamilton, J.A.: Ionization behavior of aqueous short-chain carboxylic acids: a carbon-13 NMR study. J. Lipid Res. 23(5), 795-799 (1982)

50. Chang, C., Muccio, D.D., St. Pierre, T.: Determination of the tacticity and analysis of the $\mathrm{pH}$ titration of poly(acrylic acid) by proton and carbon-13 NMR. Macromolecules 18(11), 2154-2157 (1985)

51. Buckingham, A.: Chemical Shifts in the Nuclear Magnetic Resonance Spectra of Molecules Containing Polar Groups. Can. J. Chem. 38(2), 300-307 (1960)

52. Schneider, W.G., Bernstein, H.J., Pople, J.A.: Proton Magnetic Resonance Chemical Shift of Free (Gaseous) and Associated (Liquid) Hydride Molecules. J. Chem. Phys. 28(4), 601 (1958)

53. Neal, S., Nip, A.M., Zhang, H., Wishart, D.S.: Rapid and accurate calculation of protein ${ }^{1} \mathrm{H},{ }^{13} \mathrm{C}$ and ${ }^{15} \mathrm{~N}$ chemical shifts. J. Biomol. NMR 26(3), 215-40 (2003)

54. Platzer, G., Okon, M., McIntosh, L.P.: pH-dependent random coil ${ }^{1} \mathrm{H},{ }^{13} \mathrm{C}$, and ${ }^{15} \mathrm{~N}$ chemical shifts of the ionizable amino acids: a guide for protein $\mathrm{p} K_{\mathrm{a}}$ measurements. J. Biomol. NMR 60(2-3), 109-129 (2014)

55. Manning, G.S.: Limiting Laws and Counterion Condensation in Polyelectrolyte Solutions I. Colligative Properties. J. Chem. Phys. 51(3), 924-933 (1969)

56. Reith, D., Müller, B., Müller-Plathe, F., Wiegand, S.: How does the chain extension of poly (acrylic acid) scale in aqueous solution? a combined study with light scattering and computer simulation. J. Chem. Phys. 116(20), 9100-9106 (2002)

57. Callaghan, P.T., Pinder, D.N.: A pulsed field gradient NMR study of self-diffusion in a polydisperse polymer system: dextran in water. Macromolecules 16(6), 968-973 (1983)

58. Kulicke, W.M., Clasen, C.: Viscosimetric Determination of the Molar Mass. In: Viscosimetry Polym. Polyelectrolytes, Springer Laboratory, pp. 69-89. Springer Berlin Heidelberg, Berlin, Heidelberg (2004)

59. Dunn, L., Stokes, R.: The diffusion of monocarboxylic acids in aqueous solution at $25^{\circ}$. Aust. J. Chem. 18(3), 285-296 (1965)

60. Cranford, S.W., Buehler, M.J.: Variation of Weak Polyelectrolyte Persistence Length through an Electrostatic Contour Length. Macromolecules 45(19), 8067-8082 (2012) 